
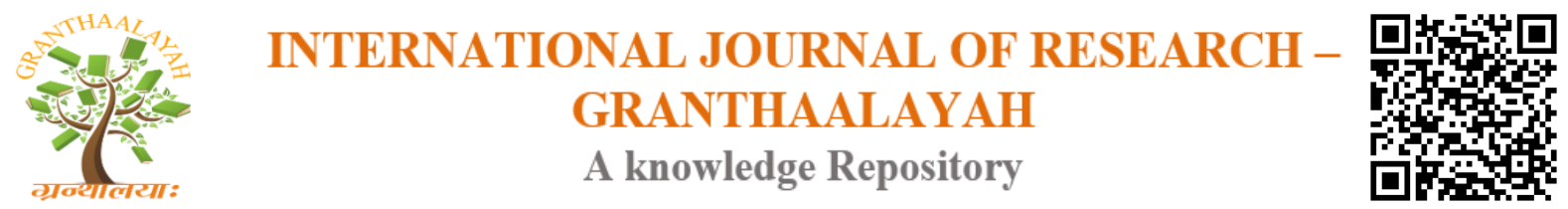

Management

\title{
EFFECT OF INFORMAL NETWORKS ON ENTERPRISE TRANSITION IN ELDORET, KENYA
}

\author{
Zakayo Kibet Tallam ${ }^{* 1}$, Dr Benard Nasiuma ${ }^{2}$ \\ ${ }^{* 1}$ Department of Entrepreneurial Studies, Moi University \\ ${ }^{2}$ Department of Development Studies Moi University
}

\begin{abstract}
Despite the wide application of Informal Networking, there is still limited understanding on the phenomenon in enterprise continuum. This study analysed a comparative study on Informal networks and Enterprise transition: Case of Eldoret, in Kenya. The study was informed by Reeg's onion model, it adopted a post-positivism research. Data was adopted from a thesis, where it was collected using questionnaires. A survey research design was employed. Multiple regressions were used to measure: Effects and strength of the relationship. AMOS was used for: Modeling, Likelihood approval, Nested and Hypothesis testing. The $\mathrm{p}<=0.05$ was considered statistically significant. Findings indicate: an average of $\mathrm{KMO}=0.80$. Entrepreneurial drivers on informal networks, had a negative influence; Informal networks had a positive influence on enterprise transition; public networks on enterprise transition had a negative influence; informal networks, public networks and private networks enters the model, all the results are significant, indirect effect of public networks and private networks was supportive.
\end{abstract}

Keywords: Entrepreneurial Drivers; Private Networks; Private Networks.

Cite This Article: Zakayo Kibet Tallam, and Dr Benard Nasiuma. (2017). "EFFECT OF INFORMAL NETWORKS ON ENTERPRISE TRANSITION IN ELDORET, KENYA." International Journal of Research - Granthaalayah, 5(12), 392-400. https:// doi.org/10.29121/granthaalayah.v5.i12.2017.526.

\section{Introduction}

\subsection{Background}

Studies have argued that the success of SMEs in Egypt depend on the public networks (Hampel, Milagrosa, Loewe \& Reeg, 2013; ILO, 1995 and Rosa, 1997). While that of (Liedholm and Mead, 1987) in Bangladesh, Sierra Leone, Honduras, Thailand and Egypt found that in the segment of enterprises of four or less workers, only $1 \%$ transit to the next size category of more than 10 workers. In Thailad Audretsch and Thurik (2004) mention, “Thorton\& Flynne (2003) and Saxenian (1994) argue that successful Entrepreneurial transition are characterized by thriving supportive networks that provide the institutional fabric; linking individual 
entrepreneurs to organized sources of learning and resources. Hence, individual Informal networks and inter-organizational strategic network activities are important to a successful startup and to an ongoing competitive advantage as they may constrain or facilitate resource acquisition and the identification of new opportunities (Hindle, 2006; Beckert, 2010).

In sub Saharan countries a study by (Víctor Pérez Centeno, 2014; Szarka, 1990) content that the entrepreneurial networking as a specific type of relation linking a set of persons, object or events. The drivers of entrepreneurial networking influenced the enterprise transition in the enterprise continuum, for this incident private networking has not been well realized (Sagasti \& Kuramoto, 2003; Villarán, 2010). According to (Stokes et al., 2010) entrepreneurial networking have become a widespread phenomenon all around the world and entrepreneurial networking undergoes a pattern of various stages from start-up, development and growth through to decline and closure.

With African nations being dominantly patriarchal, the extent to which SMEs are able to freely participate in entrepreneurship activities will largely be determined by the existing cultural atmosphere (Serida et al., 2012). In this regard, Kiriti et al. (2003a) observe that African culture continues to be a barrier to development because it perpetuates culturally sanctioned biases against a number of SMEs for which have resulted in lower intentions for participation of women in business activities Moraima De Hoyos-Ruperto, 2011. Existing gender research has focused attention on "gender equality" at the work place. Evidently, there are scant studies on entrepreneurial networking between gender, conducted on societies with a pattern of shared values, beliefs and traits which are ideally associated with culture. Further, much of the evidence on gender-related entrepreneurial activity comes from studies based in the United States and European countries; placing the generalization of these findings in an African setting in question, Víctor Pérez Centeno, 2014. This is considered an important research gap in the current study if, as the Kenyan nation, we have to address the gender disparities in entrepreneurial activities and its resultant limitations.

Entrepreneurial Networking are regarded quasi as they are expected to inhibit some amount of regularity and durability, all the same informal networks is still yet to be achieved Moraima De Hoyos-Ruperto, 2011. Entrepreneurial networking defers from enterprise to enterprise by the degree of formalization of relations and by type of coordination, the concept of informal networks are about private actors participating in decision making processes not subjected to majority control, Loewe \& Reeg, 2013. Aggregation and mediation of interest is of course important in all politics, however, the criteria for obtaining the informal networks mediating effect between entrepreneurial drivers and enterprise transition has not been clearly undertaken (Serida et al., 2012).

Advantage (Corbett, Covin, O'Connor, \& Tucci, 2013; Phan, Wright, Ucbasaran, \& Tan, 2009; Burt, 1992). Singh et al., (1999) in their study found out that the size and number of weak ties in an entrepreneur's social network were positively related to the number of new venture ideas and opportunities recognized. Moreover, network entrepreneurs were found to identify significantly more opportunities than solo entrepreneurs Víctor Pérez Centeno, (2014). 
This study is significant for it provides a new and rich seam of information of entrepreneurs of hardware and electrical enterprises in Nakuru town, Nakuru County. In addition, the findings on how entrepreneurs actually network may help the hardware and electrical enterprises to identify their networking weaknesses, and accelerate their network efforts. These studies improve understanding of the network-building process in Nakuru County, Kenya

\section{Literature}

Public network: Public entrepreneurship networks acknowledge shifts in institutional resources among private sector and citizens groups that have moved the locus of initiative and change outside the state. Policy development increasingly occurs in an intermediate arena that is neither governmental nor private. Interaction and negotiation between the government and the private sector has become unavoidable as firms have developed internal capacities for analysis and action. Their increasing competence has highlighted the importance securing their active participation to make policy effective. Environmental and citizens groups have increased their capacity to pursue their aspirations outside of state policy. The cases reviewed in this report acknowledge these trends, but suggest that successful policy-making still depends on the ability of the government to work collaboratively with the private sector and citizens groups. At the same time, the robustness of this institutional transformation means that strategies for pursuing sustainable development will need to be synchronized with changes in organizational relationships.

Our approach explores an insight compatible with this emerging institutional environment. One way that radical change happens in complex systems is when "something starts somewhere and grows." PEN is our model to capture the dynamics of change and the implications for action by government agencies and other actors interested in sustainable development. Five key features distinguish public entrepreneurship networks: A pattern of inter-organizational cooperation that spans public, private, and civic spheres and develops through, Interaction in problem centered networks, Public regarding local initiative supported by a set of Specific organizational roles related in an Institutional ecology that facilitates development.

\section{Methodology}

\subsection{Study Area, Research Design, Target Population and Instruments}

Data was adopted from a thesis, it was collected using questionnaires. A survey research design was employed. This study was conducted in Nakuru Town in Nakuru County, Kenya and the Data for this study were collected through a questionnaire survey and the populations of interest consist of all the entrepreneurs of hardware and electrical enterprises in the county.A survey research design was deployed in the study. A survey research is the collection of data from a population for purpose of description or to identify co-variation between variables that may point to causal relationships or predictive pattern of influence, Roger (2007). The target population in this study was 1085 registered and licensed Hardware and electrical enterprises. This study was interested in carrying out research in Nakuru Town in Nakuru County, Kenya. Data Collection Instrument .This study was conducted using a survey administered questionnaire to test the 
proposed model The study was specifically designed to test the validity of the theoretical measurement model and hypothesized relationships among the constructs

\section{Analysis and Finding}

Multiple regressions were used to measure: Effects and strength of the relationship. AMOS was used for: Modeling, Likelihood approval, Nested and Hypothesis testing. The $\mathrm{p}<=0.05$ was considered statistically significant. Findings indicate: an average of $\mathrm{KMO}=0.80$

\subsection{Multiple Regressions were used to Measure: Effects and Strength of the Relationship}

Furthermore, finding indicate that Informal networks had a positive influence on enterprise transition $(\beta=.719, t=6.727, \rho<.000)$. Hence this study suggests that Informal networks are a strong contributor of entrepreneurial drivers, therefore the null hypothesis $\mathrm{H}_{2 b}$ is rejected.

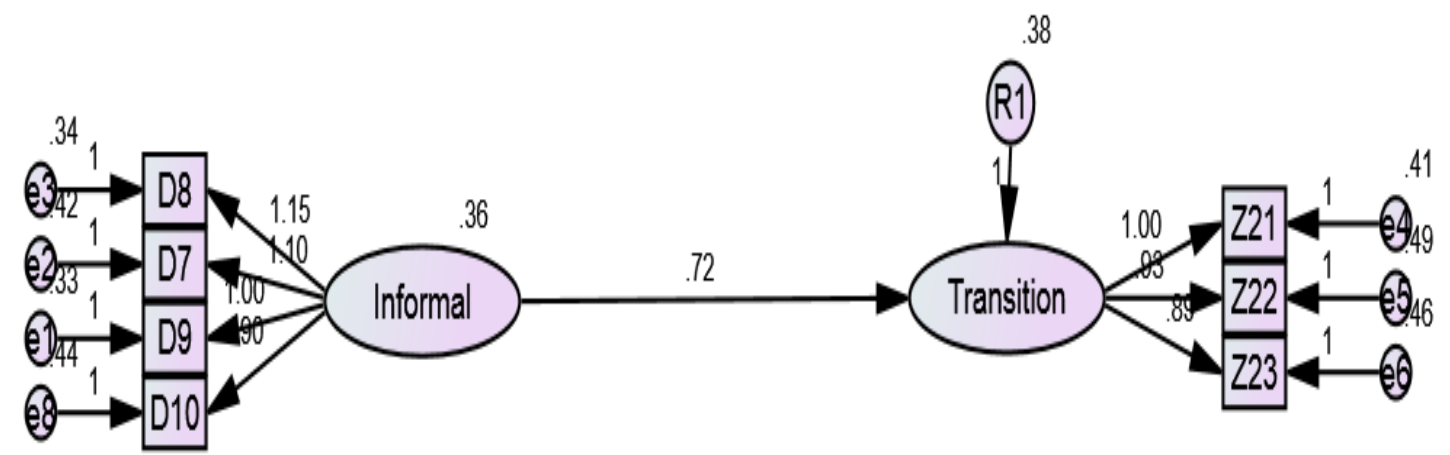

Figure 4.14: Direct Effect from informal networks to enterprise transition

Table 4.23: Summary of estimates before mediator (informal networks) variable enters the model.

\begin{tabular}{|c|c|c|c|c|c|}
\hline & Estimate & S.E. & C.R. & $\mathrm{P}$ & Label \\
\hline Transition <--- Informal & .719 & .107 & 6.727 & $* * *$ & Sign \\
\hline
\end{tabular}

\subsection{AMOS to Test the Hypothesis $\mathrm{H}_{2 \mathrm{c}}$}

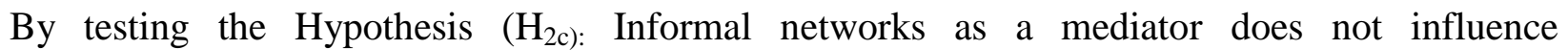
entrepreneurial drivers and enterprise transition. This study established that after the mediator (informal networks) variable enters the model (Figure 4.15 and Table 4.24) it shows that $\beta-.228$ reduced to -.122 and the results is significant since the $p=0.000$ which is less than 0.05 . We can see that entrepreneurial drivers have significant effect on informal networks and informal networks have significant effect on enterprise transition. So, the type of mediation here is partial mediation since the direct effect of entrepreneurial drivers on enterprise transition is still significant after the informal networks enters the model even though beta estimates are reduced. Thus, we can conclude that entrepreneurial drivers have significant direct effect on enterprise transition and also significant indirect effect on enterprise transition on mediating variable informal networks, therefore the null hypothesis $\mathrm{H}_{2 \mathrm{c}}$ is rejected. 
In general, results indicate that entrepreneurial drivers on informal networks when tested by multiple regression and special process procedure both yielded results which showed that entrepreneurial drivers were not supportive to enterprise transition, while result when employed technique of AMOS, indicate a negative with $\beta=-.156$.

Table 4.25: Regression coefficient to predict public networks from entrepreneurial drivers

\begin{tabular}{|c|c|c|c|c|c|c|}
\hline \multicolumn{7}{|c|}{ Coefficients $^{\mathrm{a}}$} \\
\hline \multirow{2}{*}{\multicolumn{2}{|c|}{ Model }} & \multicolumn{2}{|c|}{$\begin{array}{l}\text { Unstandardized } \\
\text { Coefficients }\end{array}$} & \multirow{2}{*}{\begin{tabular}{|c|}
$\begin{array}{c}\text { Standardized } \\
\text { Coefficients }\end{array}$ \\
Beta \\
\end{tabular}} & \multirow[b]{2}{*}{$\mathbf{t}$} & \multirow[b]{2}{*}{ Sig. } \\
\hline & & B & Std. Error & & & \\
\hline \multirow[t]{2}{*}{1} & (Constant) & .592 & .032 & & 18.499 & .000 \\
\hline & DRIVERS & .115 & .045 & .157 & 2.566 & .011 \\
\hline
\end{tabular}

c. 115

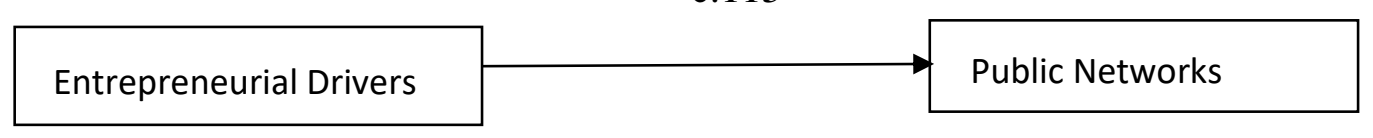

$* \mathrm{p}<.05, * * \mathrm{p}<.01, * * * \mathrm{p}<.001$, all two tailed.

\subsection{Coefficient Entrepreneurial Drivers: Public Networks}

The results yielded by this study indicated that, values obtained are also used to test the null hypothesis $\mathrm{H}_{0}$ : $\mathrm{cf}=0$. When the units in the variable measured are not meaningful or not easy to interpret (Warner, 2013).

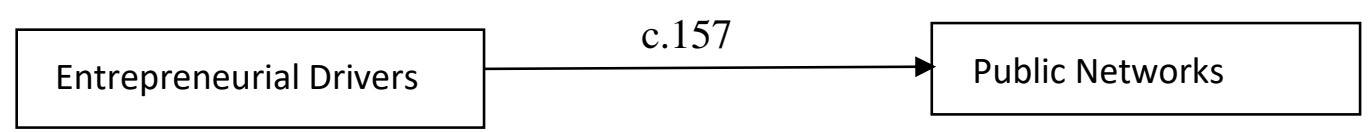

$* \mathrm{p}<.05, * * \mathrm{p}<.01, * * * \mathrm{p}<.001$, all two tailed.

Figure 4.17: Standardized coefficient from drivers to public

\subsection{Multiple Regressions: Public Networks and Enterprise Transition}

This study conducted analysis to assess effect of Public Networks on Enterprise Transition. The results for regressions show that paths coefficient for standardized path coefficient (0.001), with $\mathrm{t}$ $(259)=-.025, p=.980$., as shown on (figure 4.18). Hence this study has no otherwise but to conclude that Public Networks has no effect on Enterprise Transition.

\section{Standardized Coefficient}

According to Keith (2006), a standardized coefficient ( $\beta$ ) or Factor loading as suggested by Ananda (2010) of less than .05 suggests a negligible effect; a standardized coefficient of .05 to .10 suggests a small but meaningful effect; a standardized coefficient of .10 to .25 means a moderate effect, and a standardized coefficient of above. 25 represent a large effect. According to Ananda, (2010), a 
Standardized Regression Weight is also known as a Factor Loading, while Squared Multiple Correlation is expressed as R2. Study by Sanja M., (2017) in his study on the use of IFMIS system in the Kenyan public sector ,attest that its essential consider a standardized coefficient $(\beta)$ which generates ranges with a mathematical series of coefficient $(0.15$ on inreamantal level $)$ with expressions: Negligible effect for $(\beta<.05)$, Low effect for $(\beta=.10$ to .40$)$ moderate effect for ( $\beta=.40$ to .55$)$,Strong effect $(\beta=.55$ to .70$)$ and Excellent effect $(\beta=<.80)$. This research basing on the above standardized coefficient deduce that, Public Networks $(\beta=0.001)$, is said to be Negligible effect for $(\beta<.05)$ (Sanja ,2017: p162), which concurs with the of Keith (2006), on the initiative scale.

Finding also indicate that Informal networks had a positive influence on enterprise transition $(\beta=$ $.719, t=6.727, \rho<.000)$. Hence this study suggests that Informal networks are a strong contributor of entrepreneurial drivers, therefore the null hypothesis $\mathrm{H}_{2 b}$ is rejected. Finding also indicate that, The results for regressions show that paths coefficient for unstandardized path coefficient $(-0.001)$, with $\mathrm{t}(259)=-.025, \mathrm{p}=.980$. Similar research teams have shown similar findings as the MSU/USAID group provides further evidence that small enterprises rarely grow. Biggs et al. (1999) indicated that less than 10\% of Informal networks in the size-class with fewer than 10 workers ever grow to the 10-49 workers' category in the five Sub-Saharan countries.

In the next size-class (10-49 employees), where more Informal networks tend to be formal and entry costs are higher, there was more mobility: 22\% of the firms (most with start-up sizes averaging about 40 employees) had been able to grow beyond their size-class since their inception (average firm age in their survey was 12 years). In turn, a World Bank report (1993) in Ghana, Kenya, Zimbabwe and Cameroon estimated slightly higher rates. It established that over a period of 5-6 years the Informal networks in Ghana was $20 \%$ and in Kenya $10 \%$. The microenterprises (less than 10 workers) almost never jump two categories to become medium enterprises (more than 50 workers). This results concurs with the of Keith (2006), on the initiative scale. This research content that Public Networks does not support Enterprise Transition.

However, Nasiuma (2016) ,contend that the higher Informal networks estimated by his study reported a similar characteristics of Informal networks with Public Networks, which covered enterprises of workers in the manufacturing sector only. Entry costs then are higher than in the trade and services sector, because producing goods entails more planning, larger investments and higher risks. Entrepreneurs in that sector would therefore be more growth-oriented than in the services area

\subsection{Chi-Square Distribution}

This study utilized the indicator the strength of the effect among variables known as Bartlett's test of sphericity. Results established indicated that Bartlett's test of sphericity was adhered to. Sanja., (2017:p154) In his PhD thesis showed that Bartlett's test of sphericity was equivalent Chi-Square distribution, his research obtained Chi-Square value $(\chi 2=637.882$, $\mathrm{df}=105)$ which termed as fairly large, it means that the data suitable to use principal component analysis. (Hui, 2011) results agreed with sanja's finding, but delivered observed significance level as .000. It is concluded that the strength of the effect among variables is strong. It is a good idea to carry out a 
factor analysis for the data, hence this study went ahead to carry out a factor analysis. A recent ILO report on African women entrepreneurs (2004) in Ethiopia, Zambia and Tanzania found that the vast majority of women-owned enterprises start very small and rarely grow beyond five workers, if they grow at all. They generally employ only the owner and very few graduate to the small and medium-sized categories (above 10 workers).

Indeed, Informal networks are quite exceptional for the MSE sector in general, but even more among women-owned enterprises. The larger the size of a firm, the most unlikely it is to find a woman proprietor. In the countries where the research was conducted, it is difficult for women to access the skills and resources necessary to move out of the micro-enterprise scale and beyond. The result on Informal networks is the same for Botswana, Kenya, Malawi, Swaziland and Zimbabwe: just $1 \%$ of the microenterprises that started with 1 to 4 workers employed 10 or more workers in the long run (Mead, 1994). According to (The small business project, 2009), Entrepreneurial Networking has become more and more indispensable in the entrepreneurial world; however, entrepreneurial networking has not been attained well.

Study by Nasiuma (2016) on entrepreneurial drivers found out that informal networks when tested by multiple regression and special process procedure both yielded results which showed that entrepreneurial drivers were not supportive to enterprise transition, while result when employed technique of SEM, indicate a positive with $\beta=146$.

\subsection{Analysis of Partial Least Squares}

In utilizing Partial Least Squares, this study emulate research done by Sanja and Rdrigues (2017) on Analysis of Partial Least Squares with Split Path Models it echoed ML which attempts to maximize the likelihood that obtained values of the criterion variable since it was correctly predicted by (Hair et al., 2006) and also supported by Arbuckle (2013), the idea of maximum likelihood has been appraised by (Ananda 2011). PLS-regression models are an alternative to OLS regression or canonical correlation. PLS regression has been used, for instance, for econometric growth modeling (Korkmazoglu \& Kemalbay, 2012). Comparing OLS and PLS regression, one simulation study Temme, Kreis, \& Lutz, (2006: 20) found that the results for simulated data vary on Entrepreneurial Networking similar to those resulting from OLS regression." Becker et al., (2013: 676), warns,-A repeated application of PLS-POS with different starting partitions is advisable to avoid local optima.l Different starting positions will occur automatically with each run of the model. Wedel \& Kamakura (2000), endorsed by Becker et al., (2013), recommend running the PLS-POS algorithm several times to attain alternative starting partitions and, finally, to select the best segmentation solution.

\subsection{Factor Loading (FL)}

Factor Loading was examined by observing the factors of each item; hence a total of 300 items were examined. According to Hinkin (1995), the item should be dropped if factor loading is less than 0.5 signifying lack of reliability while if the significance of more than 0.5 the item was considered reliable and it was not dropped hence, it was to be provided forward for further analysis. EFA was fundamentally used to reduce large number of variables down to a smaller number of components. This study chose this method because it aimed at extracting maximum 
variance from, three hundred and six (306) dataset within each factor (Chatfield and Collins, 1992).

In the empirical work of Costello and Osborne (2005) on best practices in exploratory factor analysis, this study recommended the use of Principal Component Analysis (PCA) since it has the potency of revealing the underlying structure of the latent variables, for example, system, technical operation skills, management skills, IT infrastructure with an appropriate rotation method. Nasiuma B., \& Sanja ,M ., (2014) on factor analysis by rotation methods with virmax found out that Maximum Likelihood or Principal Axis Factoring) gives the best results, depending on whether your data are generally normally-distributed or significantly non-normal, respectively, comparing with results in this study entrepreneurial drivers responded well on data well which was basically supportive to enterprise transition.

\section{Conclusion}

In conclusion , among the null hypothesis tested, finding indicates that Entrepreneurial drivers on Informal networks had a positive influence on enterprise transition; Entrepreneurial drivers on public networks had a positive influence; public networks on enterprise transition had a negative influence; Entrepreneurial drivers had a positive influence on private networks; private networks had a positive influence on enterprise transition. All the results are significant; so, all the type of mediations here are partial mediations. This study concludes that direct effect of Informal networks on enterprise transition was not supportive, while public networks and private networks was supportive, but informal networks was not. all the results are significant, while indirect effect of public networks and private networks was supportive, but informal networks was not.

\section{Recommendation}

This study recommends the creation of suitable environment that could enhance entrepreneurial networking in order for enterprises to transit in the enterprise continuum. A model developed (DENET) that contributes to the body of knowledge in entrepreneurial networking.

\section{Reference}

[1] Audretsch, D., \&Thurik, R., (2004). A model of the entrepreneurial economy. Papers on Entrepreneurship, Growth, and Public Policy. Jena, Germany: Group Entrepreneurship, Growth and Public Policy.

[2] Aulakh, P., S., \& Gencturk, E., F., (2000). International principal-agent relationships: Control, governance and performance. Industrial Marketing Management, 29, 521-538.

[3] Auster, E., (1990). 'The Inter-Organizational Environment: Network Theory, Tools, and Applications', in F. Williams and D. Gibson (eds.), Technology Transfer: A Communication Perspective, Sage, 63-89.

[4] Bridge, B., O’Neill, K., and Cromie, S., (1998). 'Understanding enterprise, Entrepreneurship and small Businesses', MacMillan Business: London

[5] Brüderl, J., Preisendörfer, P. (1998). Network Support and the Success of Newly Founded Businesses, Small Business Economics 10, pp. 213-225 Donckels, R., and Lambrecht, J., (1997). The Network Position of Small Businesses: An Explanatory Model', Journal of Small Business Management, April: 13-25. 
[6] Donckels, R., and Lambrecht, J., (1995),'network and small business growth: An Explanatory model', small business economics, Vol 7, pp. 273-89

[7] Hampel-Milagrosa, A.,(2013): micro and small enterprises upgrading in Philippines: The role of entrepreneur, enterprise, networks and the business environment, Bonn: DIE, (study)

[8] Hanks, S.,H., Watson, C.,J., Jansen, E., and Chandler, G.,N., (1993), 'Tightening the Life-Cycle construct: A study of Growth Stage configurations in High-Technology organization', Entrepreneurship: Theory and Practice, vol. 18(2)pp. 5-29

[9] Humphery, J., and Schmitz, H., (2000): governance and upgrading: linking industrial Cluster and global value chains research, London institute of development studies (Working paper 120)

[10] Hoang, H., and Antoncic. B., (2003). Network based research in entrepreneurship: A Critical review. Journal of business venturing, 18(2): 165-87

[11] ILO, (2004). Supporting growth-oriented women entrepreneurs in Ethiopia, Kenya \&Tanzania: Overview Report, International Labour Office (ILO), SEED Programme\& African Development Bank (AfDB), Private Sector Department (OPSD).

[12] Jack, S., (2010) Approaches to studying networks: implications and outcomes. Journal of business venturing, 25(1), 120-137

[13] Liedholm, Carl and Mead, Donald. (1987) "Small scale industries in developing countries: Empirical evidence and policy implications", MSU international development Paper No. 9, 1987.

[14] Lindley, P., \& Walker, S., N., (1993). Theoretical and methodological differentiation of Moderation and mediation. Nursing research, 42, 276-279

[15] Mead, D., (1994). The Contribution of Small Enterprises to Employment Growth in Southem and Eastern Africa. World Development, 22(12), 1881-1894.

[16] Mead, D., (1999). MSEs tackle both poverty and growth (but in differing proportions). In K. King \& S. McGrath (Ed.), Enterprise in Africa: between poverty and Growth. London: Intermediate Technology Development Group Publishing.

[17] Mead, D., \&Liedholm, C., (1998). The Dynamics of Micro and Small Enterprises in Developing Countries. World Development, 26(1), 61-74.

[18] Sanja , Michael ,Mutongwa , (2017).PhD Thesis, Department of Computer Science and software engineering, School of Informatics and Innovation Systems, Jaramogi Oginga Odinga University of Science and Technology Page;120-140;168 -170

[19] Saxenian, A., (1994). Regional advantage: Culture and competition in Silicon Valley and Route 128. Cambridge: Harvard University Press.

[20] Serida, J., Morales, O., \& Nakamatsu, K. (2012). Global Entrepreneurship Monitor Peru 2011 (pp. 146). Lima: Universidad ESAN.

[21] Sessional paper no. 2 of 2005 on development of micro and small enterprises for Wealth employment creation for poverty reduction, Government printers, Nairobi

[22] Víctor Pérez Centeno, (2014). Entrepreneurial Networking of Small Businesses in Latin-America the Case of Villa el Salvador in Peru

[23] Villarán, F. (2010). Politicas e Instituciones de Apoyo a la Micro y Pequeña Empresa en el Peru. In C. Ferraro \& G. Stumpo (Eds.), Políticas de Apoyo alas Pymes en América Latina: Entre Avances Innovadores DesafiosInstitucionales (pp. 343-384). Santiago: Comisión Económica para América Latina y el Caribe (CEPAL).

[24] Weinfurt, K., P., (1995). Multivariate analysis of variance. In K.G. Grimm \& P.R. Yarnold (Eds.) Reading and understanding multivariate statistics (pp. 245-276). Washington, DC: American Psychological Association. 